\title{
PERFORMANCE ENHANCEMENT OF A DIESEL ENGINE BY PROVIDING INSULATIONS ON ENGINE PARTS
}

\author{
Vinayagamoorthy R. ${ }^{1}$, Mothilal T. ${ }^{2}$, Madhavan S. $^{3}$ \\ ${ }^{1,3}$ Department of Mechanical Engineering, Sri Venkateswara College of Engineering, Sriperumbudur, Chennai, India. \\ ${ }^{2}$ Department of Mechanical Engineering, Velammal Engineering College, Chennai, India. \\ Email : vmmailbox@rediffmail.com
}

\begin{abstract}
About one third of the heat produced inside the cylinder during the combustion process goes as waste by transferring it to the coolant. If the amount of heat transferred to the coolant was reduced by a considerable amount, the heat would be used to perform the useful work, thus increasing the thermal efficiency of the engine. In this work a thin layer of coating was given to the piston, cylinder head, and liner. A series of numerical investigations were conducted in uncoated cylinder, insulating top surface of the piston alone, insulating cylinder head and liner and finally by insulating all the three and data were collected at different crank position. Three types of insulating materials were used for coating and analysis was done at different crank positions. The results prove that the heat transfer from the engine may be reduced to a considerable amount after coating thereby the thermal efficiency of a diesel engine would be increased.
\end{abstract}

Keywords: Insulation, piston, cylinder head, liner, crank angle

\section{INTRODUCTION}

The improvement of fuel economy(7) of an I.C. Engine has become a high priority to the researchers. Diesel engine reject two third of heat energy of the fuel, one-third to the coolant and one-third to the exhaust leaving one third as useful power output. During the intake process, the incoming charge is usually cooler than the walls and the flow velocities are high. During compression the charge temperature raises above the wall temperature and gas velocities decreases. Heat transfer is now from the cylinder gases to the chamber walls. During combustion gas temperatures increase substantially and the gas expands, which occurs on combustion, produces increased gas motion. This is the period when heattransfer rates to the walls are highest. Also, as the cylinder pressure rises, a small fraction of the cylinder charge is forced into crevice regions, resulting in additional heat transfer. During expansion, gas temperatures decrease so heat-transfer rate decrease. Heat is transferred by molecular motion, through solids and through fluids at rest, due to a temperature gradient.

Common metallic component materials like cast iron and aluminum have substantially different thermal properties; they both operate with combustion chamber surface temperatures $\left(200^{\circ} \mathrm{C}\right.$ to $\left.400^{\circ} \mathrm{C}\right)$ that are low relative to burned gas temperatures. There is substantial interest in using materials that could operate at much higher temperatures so that the heat losses from the working fluid would be reduced. Ceramic materials, such as silicon nitride and zirconia, have lower thermal conductivity than cast iron, would operate at higher temperatures, and thereby insulate the engine $(2,3)$. With these thermally insulating materials it is possible to reduce the heat transfer through the wall by a substantial amount. This approach is most feasible for diesel engines where there is the possibility of eliminating the conventional engine coolant system and improving engine efficiency.(1) Since the coolant-side heat transfer is essentially steady during each cycle, a high enough thermal resistance in the wall material can bring the net heat transfer close to zero(7).

\section{NUMERICAL MESH AND TIME STEP}

The first and important task in the process of flow simulation is the creation of a computational mesh to represent the flow domain. In the present work the mesh represents a $360^{\circ}$ of the combustion chamber. The physical model is discretized according to the mesh motion using the STAR-CD software. The models A, B and C consist of 89962, 91021 and 93709 finite volume cells respectively. A hexahedral structured mesh is used in the analysis(8). A time step of $\Delta t=1.111 \mathrm{e}-05 \mathrm{sec}$ is used throughout the present study.

\section{GOVERNING EQUATIONS}

The governing equations of fluid flow represent mathematical statements of the conservation laws of physics.

(1) The mass of a fluid is conserved.

(2) The rate of change of momentum equals the sum of the forces on a fluid particle (Newton's second law).

The rate of change of energy is equal to the sum of the rate of heat addition and the rate of work done on a fluid 
particle (first law of thermodynamics). To predict the flow the following governing equations were solved,

(1) Continuity Equation.

(2) Momentum Equation.

\section{A. Continuity Equation}

The mass balance for the fluid element is that, the rate of increase of mass in fluid element is equal to the net rate of flow of mass into fluid element. The unsteady threedimensional continuity equation at a point in a compressible fluid is given as, $=0 \frac{\partial u}{\partial x}+\frac{\partial v}{\partial y}+\frac{\partial w}{\partial z}$

\section{B. Momentum Equations}

According to Newton's law the rate of change of momentum of a fluid particle equals the sum of the forces on the particle.

$\mathrm{X}$-component of momentum equation is,

$$
\rho \frac{D u}{D t}=\frac{\partial\left(-p+\tau_{x x}\right)}{\partial x}+\frac{\partial \tau_{y x}}{\partial y}+\frac{\partial \tau_{z x}}{\partial z}+S_{M x}
$$

Y-component of momentum equation is,

$\rho \frac{D v}{D t}=\frac{\partial \tau_{x y}}{\partial x}+\frac{\partial\left(-p+\tau_{y y}\right)}{\partial y}+\frac{\partial \tau_{z y}}{\partial z}+S_{M y}$

Z-component of momentum equation is,

$\rho \frac{D w}{D t}=\frac{\partial \tau_{x z}}{\partial x}+\frac{\partial \tau_{y z}}{\partial y}+\frac{\partial\left(-p+\tau_{z z}\right)}{\partial z}+S_{M z}$

$S_{m(x, y, z)}=$ Source momentum per unit volume per unit time in $\mathrm{X}, \mathrm{y}, \mathrm{z}$ directions respectively.

\section{BOUNDARY CONDITIONS AND ASSUMPTIONS}

In the present computational analysis symmetric boundary conditions are used and the boundary regions are mentioned below

(1) Temperature of $300 \mathrm{~K}$ is applied for the outer surface of the cylinder

(2) Temperature of $458 \mathrm{~K}$ and heat transfer coefficient of $1520 \mathrm{~W} / \mathrm{m}^{2} \mathrm{~K}$ applied inside the combustion chamber at $320^{\circ} \mathrm{CA}$

(3) Temperature of $596 \mathrm{~K}$ and heat transfer coefficient of $3002.65 \mathrm{~W} / \mathrm{m}^{2} \mathrm{~K}$ applied inside the combustion chamber at $360^{\circ} \mathrm{CA}$

(4) Temperature of $1400 \mathrm{~K}$ and heat transfer coefficient of $719 \mathrm{~W} / \mathrm{m}^{2} \mathrm{~K}$ applied inside the combustion chamber at $410^{\circ} \mathrm{CA}$.
The following assumptions were made while performing the analysis.

(1) The material is solid at all times and at all temperatures, no phase change occurs.

(2) The thermal conductivity, density and specific heat for insulating material are constant with temperature.

(3) The effects of radiation have been neglected.

\section{METHODOLOGY}

Two dimensional and three dimensional cylinder assembly model for uncoatedcylinder, insulated piston, insulated cylinder head and liner, insulated cylinder head, liner and piston configuration (5)were done in PRO-E WILDFIRE 2 at $320^{\circ}, 360^{\circ}$ and $410^{\circ}$ crank angles separately and model were meshed in HYPERMESH to generate the finite element mesh and the meshed models were imported to ANSYS. Position of the piston for each five-degree of CAwas determined by using the equation

$y=1+a(1-\cos \theta)-\left(l^{2}-a^{2} \sin ^{2} \theta\right)^{1 / 2}$

Where $y$, is the position of the piston, a, the crank radius, $\theta$, the crank angle and I, the connecting rod length. Heat transfer convection co-efficient for each five degree of $\mathrm{CA}$ is determined by using the equation

$\mathrm{h}=130 \mathrm{~V}^{-0.06} \mathrm{P}^{0.8} \mathrm{~T}^{-0.43}\left(\mathrm{~S}_{\mathrm{p}}+1.4\right)^{0.8}$

Where $h$, is the heat transfer co-efficient, $V$, the displacement volume, $P$, the pressure and $S_{p}$, the mean piston speed. Steady state thermal analysis was carried for the above-mentioned configurations. Temperature distribution across the cylinder and the heat flux distribution across the cylinder were determined for the four above-mentioned configurations. Graph has been plotted to compare heat flux at cylinder wall for all insulated and non-insulated configuration.

\section{A. Heat Transfer to the coolant at $320^{\circ}$ Crank Angle}

Heat transfer to the coolant at $320^{\circ}$ crank angle for the four models in $3 \mathrm{D}(8)$ configurations have been analyzed and shown in fig. 4 to 7

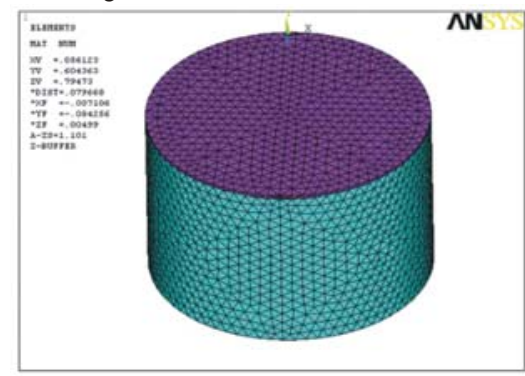

Fig. 1. Meshed model of the piston coated on the top surface 


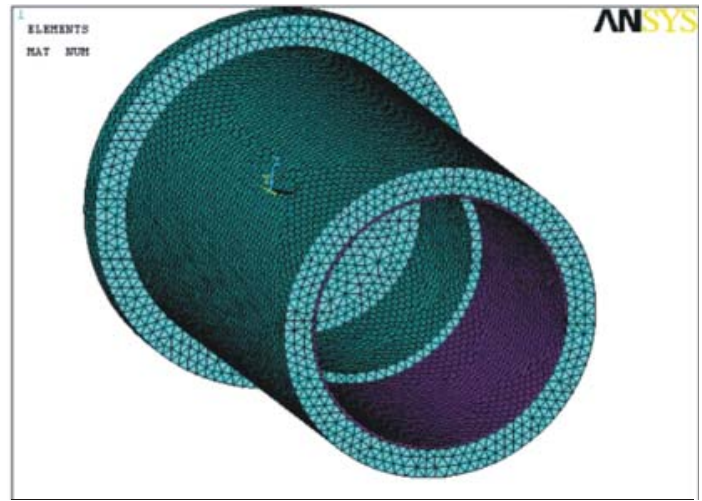

Fig. 2. Meshed model of cylinder head and liner coated

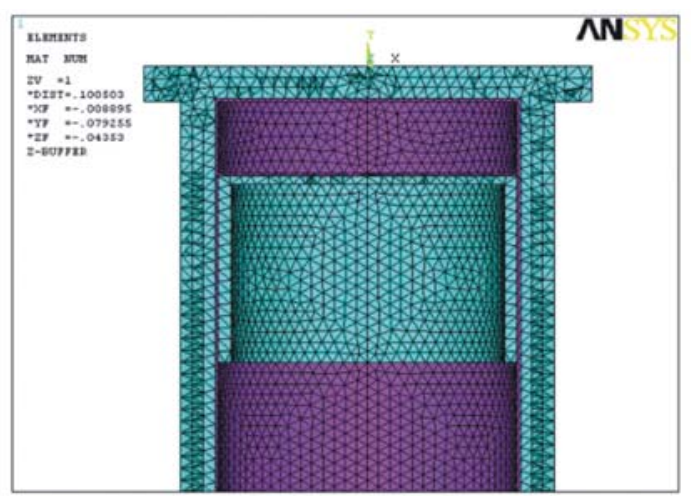

Fig. 3. Meshed model of piston, cylinder and liner coated

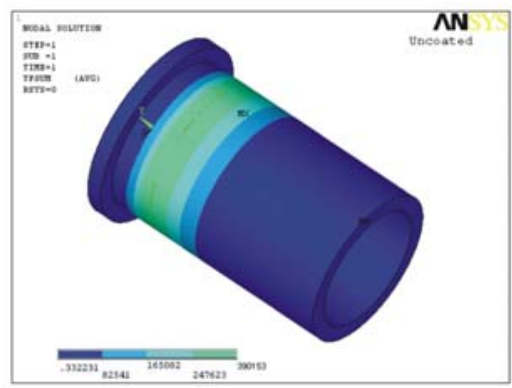

Fig. 4. Heat transferred for cylinder head

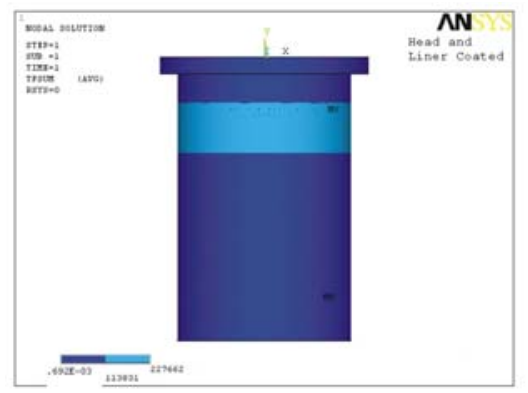

Fig. 5. Heat transferred for liner coated model

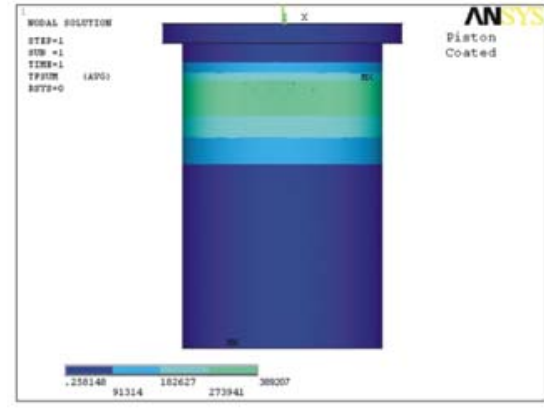

Fig. 6. Heat transferred for cylinder head

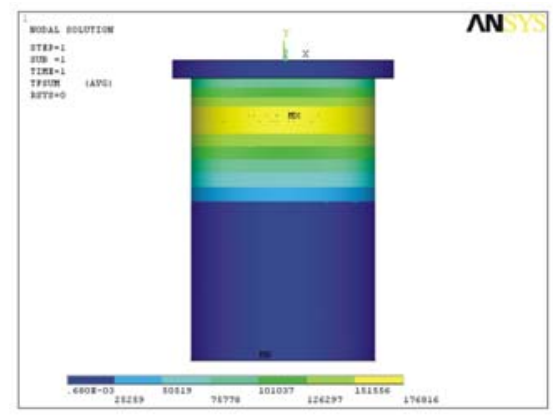

Fig. 7. Heat transferred for liner and piston

By comparing fig. 4 and 5 the heat transferred to the coolant is greater for uncoated model than piston coated model. This reduction in heat flux is the result of insulating the top surface of the piston. Comparing fig. 4 and 6 the heat transferred to the coolant has decreased drastically for header and liner coated model than piston-coated model. Comparing fig. 4 and 7 the heat transferred to the coolant for piston, cylinder head and liner coated model is still lesser than piston coated(3) and header and liner coated models. The similar trend was observed for other crank angles. Fig. 8 to 10 shows the variation of heat flux for all the models.

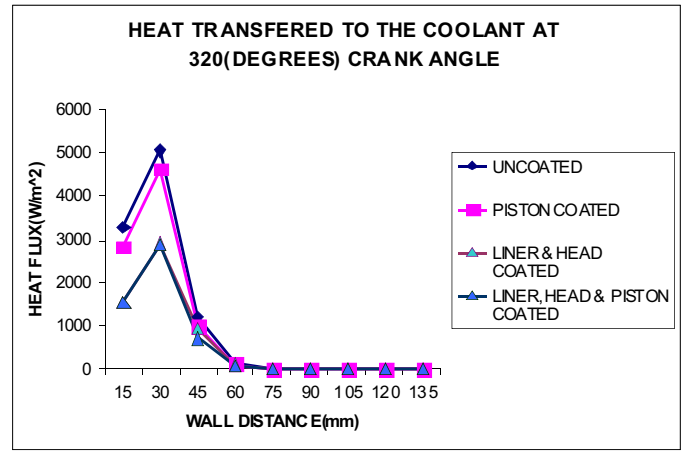

Fig. 8. Heat transferred at $320^{\circ}$ crank angle 


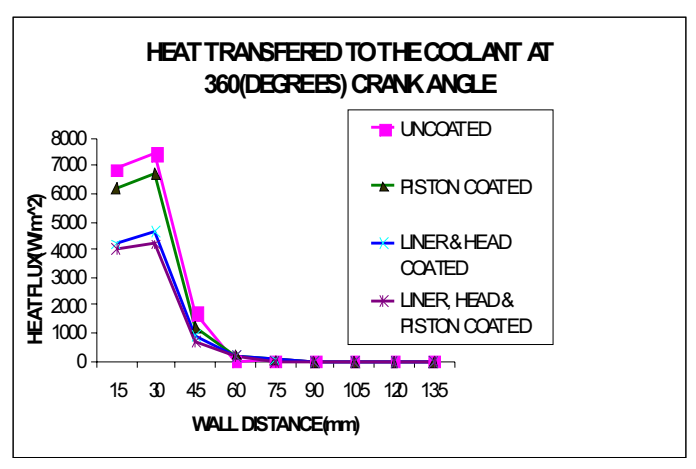

Fig. 9. Heat transferred at $360^{\circ}$ crank angle

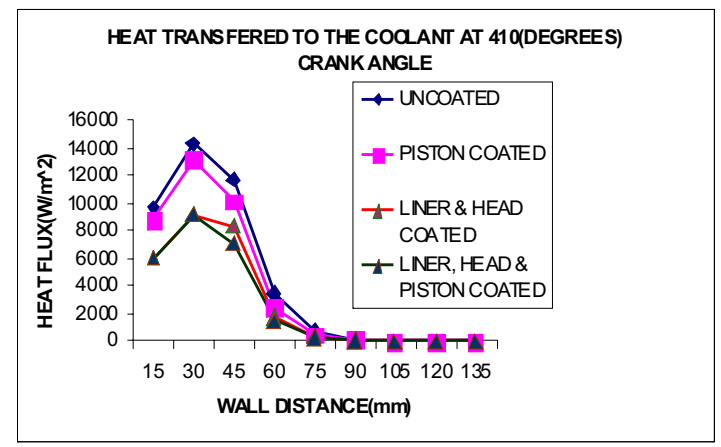

Fig. 10. Heat transferred at $410^{\circ}$ crank angle

It was observed that heat flux to coolant is maximum for uncoated model and is minimum for piston, header and liner coated model. The difference in heat flux to coolant is negligible for uncoated model and piston coated model(3) and similar trend is observed for header and liner coated model and piston, header and liner coated model. However, the difference in heat flux was found to be maximum between the uncoated and cylinder head, piston and liner coated models. Thus there is not much benefit by insulating piston top surface alone. It was observed that heat reduction to the coolant was greatly reduced when compared to uncoated cylinder by insulating cylinder head and liner(4), however only marginal reduction was obtained when coating the piston also. Insulating material like PSZ $(2,6,10)$ has low thermal conductivity so insulation reduces heat transferred to the coolant as heat flux is directly proportional to thermal conductivity

\section{B. Temperature distribution along the piston at $320^{\circ}$ Crank angle}

Temperature distribution along the piston from top to bottom was found out for all the models. The following table shows the values for $320^{\circ}$ crank angle. A similar trend was found out for the other crank angles also.
Table 1. Temperature Distribution along the piston

\begin{tabular}{|l|c|c|}
\hline \multicolumn{1}{|c|}{$\begin{array}{c}320^{\circ} \text { Crank } \\
\text { Angle }\end{array}$} & $\begin{array}{c}\text { Temperatur } \\
\text { e at the top } \\
\text { of the } \\
\text { Piston }(\mathrm{K})\end{array}$ & $\begin{array}{c}\text { Tem perature at the } \\
\text { bottom of the } \\
\text { Piston (K) }\end{array}$ \\
\hline $\begin{array}{l}\text { Uncoated } \\
\text { Cylinder }\end{array}$ & 485 & 358 \\
\hline Piston Coated & 485 & 354 \\
\hline $\begin{array}{l}\text { Cylinder Head } \\
\text { and Liner Coated }\end{array}$ & 485 & 333 \\
\hline $\begin{array}{l}\text { Piston, Cylinder } \\
\text { head and Liner } \\
\text { Coated }\end{array}$ & 485 & 323 \\
\hline
\end{tabular}

In all the cases it is evident that temperature drops uniformly from top to bottom due to resistance offered to heat transfer by the material(8). From the table. 1 it is evident that coating of piston his very little effect in resisting heat transfer.

\section{VALIDATION}

Table 2. Comparison of heat flux gain for piston, header and liner coated model With basic uncoated model

\begin{tabular}{|c|l|c|c|}
\hline Sl.No & $\begin{array}{l}\text { Crank } \\
\text { Angle }\end{array}$ & Experimental & ANSYS \\
\hline 1 & $320^{0}$ & $11 \%$ & $7.2 \%$ \\
\hline 2 & $360^{\circ}$ & $10.2 \%$ & $6.1 \%$ \\
\hline 3 & $410^{0}$ & $9.3 \%$ & $4.9 \%$ \\
\hline
\end{tabular}

It was observed that both the experimental and ANSYS results matches qualitatively. The difference obtained with the experiment is due to radiation effect

\section{RESULTS AND DISCUSSION}

Heat transfer analysis at three different crank angles namely $320^{\circ}, 360^{\circ}$ and $410^{\circ}$ where done for four models namely, uncoated basic model, piston coated model, cylinder header and liner coated model and finally the piston, header and liner coated model $(10,6)$ to analyze the amount of heat transferred to the coolant. (1)Here the results obtained at $320^{\circ}$ crank angle were discussed.

\section{CONCLUSION}

Adding insulation to the combustion chamber significantly reduces heat transfer to the coolant. Among three forms of insulations that were analyzed, insulating 
cylinder head and liner was the most effective in heat rejection(4) to the coolant. Insulating of piston top surface alone was not as benefit as insulating piston, cylinder head and liner, however volumetric efficiency $(7)$ is reduced due to insulation but it can be compensated by using turbocharger.

\section{REFERENCES}

[1] Alkidas A.C, "Performance and emissions achievements with a un cooled heavy duty single cylinder diesel engine", SAE 890144, pp.140-145.

[2] Assanis P, Wiese K, Schwazz E and Bryzik US, "The effect of Ceramic coating on Diesel engine performance and exhaust emissions",SAE 9104340, pp.146-147.

[3] Beg R.A, Bose P.K and Grosh B.B, "Experimental investigation on some performance parameters of a diesel engine using ceramic coating on the top of the piston", SAE 970207, pp.2-5.

[4] Christine Moore and John Hoehne, "Combustion chamber insulation effect on the performance of a low heat rejection Cummins V-903 engine", SAE 860317, pp.2.423-2.425.

[5] Cole R.M and Alkidas A.C, "Evaluation on an airgap insulated piston in a dividing chamber diesel engine", SAE 850359, pp.4.644-4.656.
[6] French C.C.J, "Ceramics in reciprocating internal combustion engine",SAE 841135,pp.5.107-5.118.

[7] Gerhard Woschni, Walter Spindler and Konrad Kolessa "Heat insulation of combustion chamber walls- $A$ measure to decrease the fuel consumption of I.C engines", SAE 870339, pp.4.269-4.287.

[8] Gunter F, Hohenburg, "Advanced approaches for heat transfer calculation”, SAE 790825, pp.27962801.

[9] Hoag K.L and Brands M.C, "Cummins/ TACOM Adiabatic engine Program", SAE 850356, pp.3.23.8.

[10] Miyairi Y, Matsuhisa I and Ozawa T, "Selective heat insulation of combustion chamber walls for a DI diesel engine with monolithic ceramics", SAE 890141, pp.117-128.

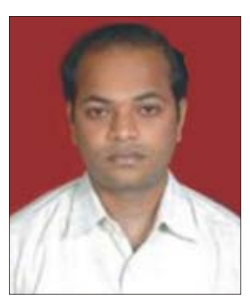

Vinayagamoorthy is a Mechanical Engineer from University of Madras and a postgraduate from Anna University. He has over seven years of teaching experience. His areas of interest are Design, Product Design and Development etc. He has published several papers in the national conferences and is currently working in the areas of welding and Mathematical Modeling. 


\title{
A REVIEW OF FRICTION WELDING PROCESSES IN SIMILAR AND DISSIMILAR MATERIALS
}

\author{
Ananthapadmanaban D., Seshagiri Rao V. ${ }^{2}$, Vijayan D. ${ }^{3}$, Muthu Vaidyanathan R. ${ }^{4}$, Prasad Rao K. ${ }^{5}$ \\ ${ }^{1}$ Research Scholar, Department of Mechanical Engineering, St.Joseph's College of Engineering, Chennai, India. \\ ${ }^{2,3,4}$ Department of Mechanical Engineering, St.Joseph's College of Engineering, Chenai, India. \\ ${ }^{5}$ Department of Metallurgical and Materials Engineering, Indian Institute of Madras, Chennai, India. \\ Email: 'ananth•1out@yahoo.com
}

\begin{abstract}
Friction welding is one of the modern manufacturing methods that is gaining importance in recent times.Many similar and dissimilar material combinations can be welded by using this method. This paper reviews the current work and research on friction welding and suggests certain areas in which there is scope for more research
\end{abstract}

Keywords: Friction welding,Dissimilar metals,Steels,Aluminium alloys, Titanium alloys,

\section{INTRODUCTION}

Friction welding method has extensively been used in manufacturing methods because of the advantages such as high material saving, low production time and possibility of the welding of parts for a long time. In the process, heat is generated by conversion of mechanical energy into thermal energy at the interfaces of the components during rotation under pressure without any energy from environment.

Friction time, friction pressure, upset time, upset pressure and rotation speed are the most important parameters in friction welding. The parameters are selected properly in the experiments since these directly affect welding quality. Generally, the friction welding methods can be examined in two types as continuousdrive and inertia welding. In continuous-drive method, one of the components is rotated at constant speed (s), while the other is pushed toward the rotated part by a sliding action under a predetermined pressure - friction pressure (Pf). Friction pressure

(Pf) is applied for a certain friction time (tf). Then, the drive is released and the rotary component is quickly stopped while the axial pressure is being increased to a higher predetermined upset pressure $(\mathrm{Pu})$ for a predetermined time (tu).

\section{DISSIMILAR MATERIAL COMBINATIONS:}

\section{A. Steels}

The following combinations have been researched upon with steel as one of the constituent metals-

(i) Medium carbon steel-Stainless steel

(ii) Mild steel-Stainless steel

(iii) Hypoeutectoid steel with 4\% Aluminium (iv) Mild steel-Alumina

(v) Austenitic to Ferritic stainless steel

Much of the early work on friction welding of steels is from the erstwhile USSR.The practical application of friction welding for manufacturing tools was recognized as early as 1957(1).Khristoforov has reported work on friction welding of small tool blanks using a lathe with suitable attachments(2).The structure and Mechanical property studies of friction welds between high speed steel and Medium Carbon Steel has been reported(3).Other researchers like Vill and Tycote have Investigated the parameters that influence the welding quality, Strength of the joint and hardness of the Heat -Affected Zone $(4,5)$. Dobrovidov et al (6) investigated the selection of optimum conditions for friction welding of High Speed steel R6M5 to Carbon steel 45.More recently, Mumim Sahin et al(7) have designed a friction welding set-up and successfully joined High speed steel and Medium Carbon steel. While using Austenitic stainless steel the following negative metallurgical changes take place during fusion welding

- delta ferrite formation

- Sigma phase

- Stress-Corrosion cracking

- Chrome -Carbide precipitate between grain boundaries at $450-850^{\circ} \mathrm{C}$ of $\mathrm{Cr}$-NiAustenitic steels

These changes can be eliminated by using friction welding.(8)

Hence, it can be seen that friction welding technology for joining steels has been fairly well developed. Table 1 shows the applications of steel joints in Industries. 
Table 1. Industrial Applications of Dissimilar steel welds

\begin{tabular}{|l|l|l|}
\hline SI.No & Product & Welds \\
\hline 1 & EN19B To EN19B & $\begin{array}{l}\text { Front Wheel Axle in } \\
\text { Automobiles }\end{array}$ \\
\hline 2 & EN354 To EN354 & Main shaft in Automobiles \\
\hline 3 & SAE 8620 To SAE 8620 & Rocker arm shaft \\
\hline 4 & $\begin{array}{l}\text { High speed steel to medium } \\
\text { carbon steel }\end{array}$ & Bimetal drill tools \\
\hline 5 & SS316 To EN8 & Pums \\
\hline 6 & SS316 To EN8 & Nozzles \\
\hline 7 & Tungsten to Copper & Electric power transmission \\
\hline 8 & SS to Al & $\begin{array}{l}\text { Nuclear and Cryogenics, } \\
\text { Chemical }\end{array}$ \\
\hline
\end{tabular}

\section{A. Joining of Austenitic to ferritic stainless steel}

Welding of ferritic to austenitic stainless steel is considered to be a major problem due to the difference in coefficient of thermal expansion which may lead to crack formation at the interface, formation of a hard zone close to the weld interface and relatively soft regions adjacent ot the hard zone. These large hardness differences between the hard and soft zones may lead to failure in service. Dissimilar metal combination between ferritic stainless steels and Austenitic Stainless Steels is commonly employed in $\mathrm{TiCl}_{4}$ reduction retorts. The austenitic stainless steel with superior creep strength and oxidation resistance are required in the high temperature regions while ferritic stainless steels are needed to avoid the problem of nickel leaching by molten Magnesium. Mechanical properties like notch tensile strength, Impact toughness, Hardness and residual stress were evaluated by friction welding, Gas Tungsten arc welding and Electron beam welding and variations in these properties were explained[9]

The effect of rotational speed on interface properties were studied by Ozdemir et al for the AISI 304L to 4340 steel combination. The microstructure was characterized by SEM methods and different regions were classified as Partially deformed zone,Deformed zone, Full Plastic deformed zone(FPDZ) and the parent metal zone.lt was found that the width of the fully pastically deformed zone is mainly affected by the rotational speed.The width and formation of the FPDZ has a detrimental effect on the mechanical strength and quality of the friction welded 304L/4340 steel couple.[10]

Dissimilar metal welds of alloy steel to mild steel have been studied by S.B.Singh et al.The study focuses on structure property correlation of weldments between mild steel and high hardness armoured plates. The effect of pre and post weld heat treatment have also been studied.[11]

\section{B. Castiron}

Very little literature is available on friction welding of cast iron.One study has observed the deformation of cast iron during friction welding. SOLIDWORKS and NASTRAN software have been used for the modeling work.[12]

\section{C.Aluminium}

Friction welding of Aluminium with Aluminium and Steel has been studied by A.Z.Sahin et al. It was found that strength of Aluminium steel welds are lower than those of Aluminium-Aluminium and Steel-Steel.Studies on Heat Affected zones have also been made.(13)Mumim Sahin et al have studied joining of severely plastically deformed Aluminium alloy(5083 alloy)With the Friction welding method.(14).

From the point of view of the welding processes,Aluminium and Copper are incompatible materials since they have a high affinity to each other at temperatures greater than $120^{\circ} \mathrm{C}$ and produce intermetallics with brittle,low strength and high Electrically resistant natures on their interface because these intermetallic compounds have a nonmetallic covalence bond(15).Thus fusion welding processes are not applicable for welding of Aluminium to Copper and solid state welding processes like friction welding have been considered.Won-Bae Lee et al(16) have studied the Aluminium-Copper Friction welded joints and found that Intermetallic Compounds, mainly $\mathrm{AlCu} \mathrm{and} \mathrm{Al}_{2} \mathrm{Cu}$ did form. When $\mathrm{Al}$ and $\mathrm{Cu}$ are joined strength of joint depends on thickness of intermetallic phases and grain size of the layer. Wollach and Davis (1977) and Nielson and Bay (1984) have found that when intermatallic phase thickness exceeds 3-5 $\mu \mathrm{m}$, brittleness of bond increases and strength decreases considerably $[17,18]$ Kearus has mentioned that if $\mathrm{Al}-\mathrm{Cu}$ is joined using friction, diffusion, explosive and cold pressure welding, intermetallic phase thickness does not exceed 3-5 $\mu \mathrm{m}$. [41] Nielsen and Bay (1984) have shown that intermetallic phase thickness does not exceed 5 um in small diameters (less than $25 \mathrm{~mm}$ ) . [4] However, when the specimen diameter exceeds $25 \mathrm{~mm}$, diffusion zone increases and intermetallic phase thickness exceeds $5 \mu \mathrm{m}$. Consequently, brittleness of bonding zone increases and its strength decreases [19].

M.Abbasi et al have mathematically determined the growth rate of Intermetallic compounds in $\mathrm{Al} / \mathrm{Cu}$ bimetal produced by cold roll welding process(20). Hence,in Aluminium-Copper combinations, it is a challenge to keep the intermetallic layer thickness to a minimum and there is scope for further research in this area. 
Partially Melted zones have been found and studied in Al-Si-Mg alloys by K.Ratnakumar et al during Gas Tungsten Arc Welding. Most of these Intermetallics are the plate like $\beta$-AlFeSi phase while a fraction of the phases can be Cubic Al(FeMn)Si phase with the so-called Chinese script like morphology(21). However, there is no mention in literature about friction welding of Aluminium Silicon alloys. There are many commercially available Aluminium alloys like 7075,6061,6063 etc ,many of them have wide applications in the Automotive and the Aerospace Industries.Joining of these alloys with themselves and to each other will be an area of research which could provide challenges to researchers in the area of friction welding.

\section{Titanium}

Titanium is an ideal pipe material for seawater systems due to its immunity to erosion-corrosion $(22,23)$. At present, Cupro-Nickel has been the pipe Material of choice for shipboard seawater systems.But this material has been beset with failures and hence titanium and its alloys could be potential replacements. Titanium and most titanium alloys are readily weldable using several welding processes(24). Post weld heat treatment is usually not necessary with the commercially pure Titanium grades(25). However, embrittlement through contamination with air and carbonaceous materials poses the biggest threat to successful welding(26).

Titanium -stainless steel joints have found application in nuclear plants. Titanium has been friction welded to 304 stainless steel successfully. Tensile tests, \% Elongation ,bend tests and corrosion tests have been carried out .Non-destructive tests like Liquid penetrant tests, radiography and ultrasonic testing have been done to evaluate the joints. Microhardness measurements have also been done. The results have been compared to the results using explosive bonding.[27] pure $\mathrm{Fe}-\mathrm{Ti}$ and $\mathrm{Ti}-\mathrm{Cu}$ systems recently by Meshram et al(28).

\section{E. Composite Materials}

It has generally been observed that there are many problems during the joining of discontinuously reinforced Aluminium matrix Composite Materials by the generally used fusion welding processes. These include Inhomogeneous distribution of the reinforcement phases, defects in the weld etc(29). Friction welding of $6061 \mathrm{Al}-\mathrm{SiC}$ Metal Matrix composites has been proved to be feasible. Raw material defects have been eliminated by extrusion and annealing processes(30). Research has also been done on 7005 Aluminium Composites by C.B.Lee et al(31).Particle fracture in MMCs friction welded joints with Silver interlayers has been studied(32)6061 Aluminium alloy composite has been friction welded with
SAE1020 steel and the effect of particle size has been studied(33).

\section{F. P/M Products}

P/M part manufacture is flexible and provides economic advantages because of the ability to press complex geometrical configurations.

P/M parts may have to be joined to each other or in some cases to other wrought materials or integrated components. Earlier,sintered components have been joined by brazing(34).Recently,there has been some work on continuos drive friction welding studies on sintered $P / M$ steel preforms to wrought copper combination(35).Analysis of the deformation of dissimilar P/M performs has also been done.In case of dissimilar metals, the difference in flow stress in the two metals can vary widely and result if non- uniform flow of the metals during simultaneous deformation(36).

\section{G. Metallic Glasses}

$\mathrm{Pd}-\mathrm{Ni}$-P/Pd-Cu-Ni-P metallic glass interfaces have been studied and characterized.(37)Friction welding of ZrTi-Cu-Ni-Be bulk metallic glasses have also been reported(38).These metallic glasses have potential applications in various structural components. (39) Friction welding of Copper based Bulk Metallic glasses to similar and dissimilar BMGs have also been tried. [43]

\section{H. Optimization of weld parameters}

Optimization of process parameters has been done for friction welded AISI 430 similar welded joints. 3 levels of 4 input parameters, namely Heating Pressure, Heating time, Upsetting pressure and upsetting time have been considered. Signal to Noise ratios have been calculated and ANOVA and pooled ANOVA analysis have been done and

significant factors have been identified.[35]In another study, parameter optimization has been carried out using simulated annealing. Here, the flash parameters like flash width,flash height and flash thickness have been measured while welding similar AISI304 steels. Graphs have been plotted showing variation of flash height, width and thickness with upsetting time,Upsetting pressure and heating pressure.Optimized parameters for mimimum metal loss for friction weldments have been plotted.[41] Automatic pipeline girth welding parameters have also been optimized. In this new variant of friction welding, a filler material in the form of an intermediate solid ring has been used. The welding ring has been positioned between the pipes. The effect of rotational speed have been studied. It was found that high rotational speeds tend to increase the welding time. Impact testing was done and 
rotational speed was optimized to give highest impact strength.[42]

\section{CONCLUSION AND SCOPE FOR RESEARCH}

Friction welding in similar and dissimilar materials has been reviewed. Based on the research work already carried out, it can be concluded that there are some grey areas that have not been focused on. The following areas are open to further research-

- Flash formation in friction welds

- Effect of rotational speed on mechanical properties

- Finite element modeling of stress and temperature in the welding zone

\section{ACKNOWLEDGEMENTS}

The authors gratefully acknowledge the support given by the Management of St.Joseph's College of Engineering, Chennai.

\section{REFERENCES}

[1] K.P.Imshennikand V.L.Golovin:Svar Proizvod, 1966, 13(1),pp.16-18.

[2] A.I.Khristoforov:Svar Proizvod., 1965, 12(5),pp3233

[3] K.G.K.Murti \& S.Sundaresan, 1986, Materials Science \& Technology, Vol2,pp.865-871

[4] V.I.Vill,1962, Friction Welding of Metals, AWS,New York

[5] R.Y.Tylecote, 1968, The Solid State Welding of Metals, Edward Arnold Ltd.,London,pp.1-50.

[6] A.N.Dobrovidov et al,Weld Proc. 22(3), 1975, pp.22-26

[7] Mumin Sahin, 2005, Journal of Materials Processing Technology 168,pp. 202-210

[8] Mumin Sahin, 2007, Materials and Design 28,pp.2244-2250

[9] V.V.Sathyanarayana,G.Madhusudhan Reddy, 2007, Journal of the Indian Welding Society

[10] Ozdimer,F.Sarsilmaz,A.Hascalik, 2007, "Effect of rotational speed on the interface properties of friction welded AISI $304 \mathrm{~L}$ to 4340 steel", Journal of Materials and Design 28,pp.301-3

[11] S.B.Singh,Tej Paul,Acase study on dissimilar welding between heat-treated alloy steel and mild steel,IWC-99,pp. 672-680
[12] Gheorge Girniceanu,Alin Stanciooiu, Studies on friction welding of cast iron, 2007, Annals of the Oradea University,VolVI(XVI),pp.1493-1497

[13] A.Z.Sahin,B.S.Yilbas and A.Z.Al-Garni, 1996, Journal of Materials Engineering and Performance,Vol5(1), pp.89-99

[14] Mumim Sahin,H.Erol Akata,Kaan Ozel, 2006, Short Communication, Journal of Materials and Design,Article in press.

[15] M.Braunovic,N.Aleksandrov, 1993, IEEE Trans. Paper No.CHMT-93-10 pp.261-268

[16] Won-Bae Lee,Kuek-Saeng Bang, Seung-Boo Jung, 2005, Journal of Alloys and Compounds 390 , pp.212-219

[17] Wallach, E.R. and Davies, G.J,1997, "Mechanical Properties of Aluminium - Copper solid - phase welds", Metals Technology, 4 183-190

[18] Nielsen. A and Bay. N.,1984, "Friction welding Copper to Aluminium",Proc, Intl Conference on Joining of Metals, JOM-2, pp.187193

[19] Kearus, W.H., 1980, "Welding Handbook" American welding society, Vol3, Miami

[20] M.Abbasi,A.Karimi Taheri, M.T.Salehi, 2001, Journal of Alloys and Compounds 319,pp.233-241

[21] K.Ratnakumar and K.Srinivasa Rao,WPQ-2007, National Conference on Welding-Productivity \& Quality, Ed.A.K.Shah

[22] Eskine,Robert.W., 1997, "Design, Fabrication, Installation and Operation of Titanium Sea Water Piping Systems", Journal of Ship Production, pp.270-287

[23] Schutz,Ronald.W and Scaturro, Milton. R., 1991, An Overview of current and Candidate Titanium Alloy Applications on U.S Navy Surface Ships,Naval Engineers Journal,pp.175-191.

[24] Oates William .R, Ed "Welding Handbook",AWS

[25] N.Ravi Chandra, "Titanium Welding in ship building Welding Productivity and Quality". Ed. A. K. Shah, pp.121-131.

[26] Markblatt DVS 2713, 2000, "Schweiben von Titanwerkstoffen GmbH,Postfach 2725,Dusseldorf 1,Deustch Titan.

[27] B.M.Ananda Rao, K.Shanmugam, U.Kamatchi Mudali, A.K.Bhaduri, K.Balachander and R.Natarajan,Developement of a Titanium/304L 
stainless steel dissimilar metal joint for the nuclear fuel reprocessing plant,IWC99,pp959-964

[28] S.D.Meshram, T.Mohandas, G.Madhusudan Reddy, 2007, Journal of Materials processing Technology 184, pp.30-337

[29] Zhang.X.P, YeLi,L.Mai, Quan. G.F,Wei. W, 1991, Aluminium Matrix composites Part A ,30:pp.14151421

[30] A.Jabaraj, P.R.Lakshminarayanan, N.Mohammad Raffi,G.Padmanaban, 2005, J.of the Indian welding Society, pp.19-25.

[31] C.B.Lin,J.Chiang Chou, C.L.Ma, 2002, Journal of materials Science 37, pp.4645-4652.

[32] C.Maldonaldo,T.H.North, 1997, Journal of Materials Science 32,pp.4739-4748.

[33] Ahmet Haslik,Nuri Orhan, 2007, Journal of Materials and Design 28,pp.313-317

[34] W.V.Knopp, 1978, International Journal of Powder Metallurgy Technology, 11(1),pp.63-65

[35] K.Jayabharath .M.Ashfaque, P.Venugopal, D.R.G.Achar, 2007, Materials Science and Engineering A, 454-455,pp.114-123

[36] B.Vamsikrishna,, P.Venugopal, K.Prasad Rao, 2004, Powder Technology 146 , pp.137-146

[37] Kawamura,T.Shoji,Y.Ohno, 2003, Journal of NonCrystalline Solids 317, pp.152-157
[38] C.H.Wong,C.H.Shek, 2003, Scripta Materialia 49 pp.393-397

[39] Takuo Shoji, Yoshihito Kawamura, Yasuhide Ohno, 2004, Materials Science and Engineering A 375377,pp.394-398

[40] Hyung-Seop Shin,Ho-Yeon Choi, Jeoung -Soo Park,Jung-Ho Ahn,Wei Zhang and Akihisa Inoue, 2008, Friction welding of $\mathrm{Cu}_{45} \mathrm{Zr}_{45} \mathrm{Ag}_{5} \mathrm{Al}_{5}$ bulk metallic glasses,Rev. Adv.Mater Sci.189,pp.104106

[41] P.Sathiya,S.Aravindan, A.Noorul-Haq, K.Panneerselvam, 2006, Optimization of friction welding parameters using simulated annealing,Indian Journal of Engineering and Material Sciences, Vol 13,pp.37-44

[42] Koen Faes,Alfred Dhooge,Patrick De Baets,Eric Vander Donckt,Wim De Waele, 2009, Parameter Optimization forautomatic pipeline girth welding using a new friction welding method, Journal of Materials and Design 30, pp.581-589

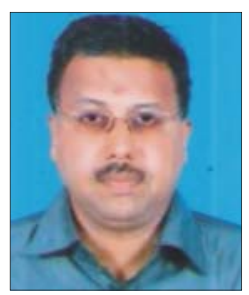

D.Ananthapadmanaban is a graduate and postgraduate from I.I.T, Madras. He is working as an Assistant Professor in the Department of Mechanical Engineering, St.Joseph's College of Engineering, Chennai. He has over 15 years of teaching experience. He is a research scholar at Sathyabama University and has published around nine papers in various Conferences and Journals. 